\title{
DISCUSIONES PROPEDÉUTICAS SOBRE TEORÍA DE LA TRANSPOSICIÓN: ACERCA DE LA AUSENCIA DE UNA TEO- RÍA DE LA ENUNCIACIÓN Y LOS PREJUICIOS DE LA SEMIÓ- TICA DE LA LITERATURA EN LA CONSIDERACIÓN DEL CINE
}

RESUMO: Neste trabalho se faz uma polêmica com dois dos mais importantes representantes da tradição semiótica literaria e do cinema, com Gianfranco Bettetini e Seymour Chatman. 0 objeto da controvérsia é mostrar como esses os autores, embora a partir de referências teóricas e diferentes tradições, podem revelar todos os tipos de preconceitos sobre os filmes, quando se considera o fenômeno da transposição de textos literários ao textos cinematográficos. Tais preconceitos vêm de deficiências ou falta de uma adequada teoria da enunciação, e tambén de um conceito antigo que busca, tanto para exigir fidelidade aos textos literários, ou tentar julgar o filme a partir dos critérios da linguagem literária.

ABSTRACT: In this paper is a controversy with two of the most important representatives of the literary and film semiotics tradition, with Gianfranco Bettetini and Seymour Chatman. The object of the controversy is to show how both authors, although from theoretical frameworks and traditions, reveal all kinds of prejudices about the movies, when considering the phenomenon of literary texts transposing film texts. Such prejudices come from deficiencies or lack of an adequate theory of enunciation, as of an old concept that seeks either to demand fidelity to literary texts, rather try to judge the film from the criteria of literary language.

1 Magister en Análisis del Discurso de la Universidad de Buenos Aires, Doctor en Historia y Teoría de las Artes de la Universidad de Buenos Aires. Autor del libro Técnica y alteridad: el robot humanoide en las transposiciones de la literatura al cine. 
PALAVRAS-CHAVE: semiótica, literatura, cinema, enunciação, transposição. KEYWORDS: semiotics, literature, film, enunciation, transposition.

\section{Introducción}

Para avanzar en el estudio del problema de la transposición es preciso primero dar un rodeo por los debates que con miras a este asunto se han suscitado en algunos lugares de la tradición semiótica literaria y cinematográfica, en especial en lo que concierne a las relaciones entre literatura y cine de acuerdo con las presuntas potencialidades de cada uno. Al respecto dos puntos de vista aparecen como inevitables, uno el de Bettetini, que se ocupa directamente del problema transpositivo, otro el de Chatman, que no tiene éste como su ocupación central pero que sí se refiere al mismo por la vía de un trabajo comparativo dedicado a exhibir las potencialidades y las flaquezas de los dos lenguajes. Para discutir sus tesis centrales nos hemos visto precisados a enfrentar una consideración semiótica de alcance más general que, si bien no está referida al mismo asunto ni se presenta en los mismos niveles, tiene sin embargo puntos en común: la identificación de las debilidades o la ausencia misma de una teoría de la enunciación adecuada para entender las peculiaridades de uno y otro lenguaje, y la ausencia, de una teoría del problema transsemiótico que trascienda los estrechos límites del inmanentismo de las técnicas y de los medios.

\section{La transposición como traducción en Bettetini: o las limitaciones de una teoría deíctica de la enunciación}

Bettetini (1996) en La conversación audiovisual,2 Las transformaciones del sujeto en la traducción, habla de traducción para referirse al pasaje de un texto literario a un texto audiovisual. Esta denominación ya introduce problemas

2 Particularmente en el capítulo 3 "Las transformaciones del sujeto en la traducción". 
y hasta limitaciones a su indagación, también, aunque no solamente, por cierta concepción de la traducción que el autor de hecho utiliza. ${ }^{3}$ Esto es, ante todo, su preocupación por la exigencia de fidelidad, aunque haya momentos en los que se aparta de dicha preocupación,. su teorización aparece así demasiado restrictiva, encuadrada en una analogía poco fecunda que le resta posibilidades explicativas a sus inteligentes intuiciones y descripciones. Nos referimos al hecho de que, cuando se piensa en una traducción, es imposible eludir el peso social que tienen el autor y el texto fuente, pues se trata de una práctica discursiva demasiado reglamentada, lo que no quiere decir que las otras prácticas no lo sean, y que está determinada por una exigencia social y hasta expectativa de fidelidad. No obstante es preciso advertir que esas exigencias no son las mismas si se trata de textos ficcionales que si se trata de otros tipos de textos -oficiales, administrativos, financieros-. Pero, en cualquier caso, lo que predomina en la lectura audiovisual, exceptuando quizás en los comienzos del cine, es la más amplia pluralidad de relaciones entre texto fuente y texto de llegada, relaciones que pueden estar determinadas en uno $\mathrm{u}$ otro grado por las exigencias y expectativas de los consumidores -ante todo expectativas de género-, pero que, en todo caso, no se hallan constreñidas a las que rigen las relaciones entre textos con fines de traducción.

Otra limitación tiene que ver con su manera de entender la enunciación audiovisual. En efecto, Bettetini permanece sujeto a una concepción de la enunciación audiovisual que no ha podido librarse de una visión antropoide,

3 En efecto, como se sabe, los estudios de la problemática de la traducción se han diversificado y complejizado, alejándose cada vez más de concepciones inmanentistas -dando peso a los problemas de la mediación cultural y de la recepción en los sistemas culturales de llegada-, y discutiendo la vieja exigencia de la fidelidad (Zohar, 1978; Toury, 1980, 1995; Lefevere, 1982, 1992; Paz, 1990). Pero incluso debe anotarse que, al menos desde el siglo XIX, la exigencia de fidelidad viene siendo impugnada., como fue el caso de los románticos en su consideración de los textos clásicos. Y, hoy se piensa incluso a la traducción en términos de reformulación (Pagliai, 2004) 
por la cual se insiste en una consideración forzada del funcionamiento audiovisual atada a las nociones de sujeto de la enunciación lingüística. ${ }^{4}$

Bettetini empieza comentando y discutiendo la "radicalización de la relación entre lenguas naturales y otros sistemas semióticos" $(1996,84)$, alegando que ésta pasa por alto que "el sentido es una actividad antes de ser un resultado" y que "el sentido es un producto antes que un dato verbalmente dado por descontado" $(1996,84)$; así, si bien reconoce los potenciales metalingüísticos propios de las lenguas, no quiere absolutizar ni trivializar esas relaciones. Pasa a considerar las transformaciones que tienen lugar en el paso de un texto lingüístico, generalmente escrito, a una materialidad audiovisual (fílmica o televisival. Destaca entonces que son los aspectos narrativos del texto los que mejor se prestan a este tipo de transformaciones, y los que aseguran mejor las continuidades. Va a insistir en que su preocupación está centrada en la relevancia atribuida a los aspectos pragmáticos de los textos vinculados por una relación transformativa.

Su tesis de partida y su guía metodológica es la siguiente:

Si un texto es un proyecto comunicativo, caracterizado por la inmanencia de un simulacro del sujeto de la enunciación, su traducción correcta y tendencialmente completa en un sistema semiótico distinto del original debería comportar también una reconstrucción analógica del mismo proyecto, debería preocuparse también de la producción de un simulacro enunciador capaz de desarrollar las mismas funciones directivas, ilocutivas y perlocutivas del primero. (Bettetini, 1996: 85).

Esto porque:

Un texto escrito remite por lo tanto a un universo semántico $y$, al mismo tiempo, a un sujeto de su enunciación, a un 'yo'

4 Ha sido Metz (1991) quien ha controvertido esta insistencia en la semiótica del cine, y quien ha logrado abrir paso a otra perspectiva teórica y metodológica. 
que habla en el intercambio comunicativo que se instaura por medio del mismo texto: este sujeto enunciador, que se disocia habitualmente en distintos sujetos textuales, es el principio ordenador de la semiosis y el principio coordinador del comportamiento comunicativo de un enunciador, de él mismo colocado como 'tú' de su posible acto relacional." (Bettetini,1996: 85). (Las negrillas son nuestras).

El autor reconoce que, debido al cambio en la materia y las sustancias expresivas, o porque el nuevo sistema semiótico no posee símbolos vacíos dispuestos para una integración indicativa, o porque lo característico de la enunciación audiovisual en el enunciado audiovisual se concreta en signos o indicios deshomogéneos respecto de los que intervienen en la configuración de su volumen semántico; la traducción de un texto escrito a uno audiovisual enfrenta muchas y complejas dificultades, a saber: el que el sujeto empírico se torne en múltiple sujetos -guionistas, dibujantes, directores etc.-; el tránsito de formas lingüísticas -vacías aunque simbólicamente dirigidas- a huellas técnicas, estrechamente vinculadas a manifestación de la materia significante; y el hecho más general de que el paso de un texto homogéneo semióticamente a otro complejo plantea no sólo dificultades para una "correcta traducción" de las huellas enunciativas, sino también la aparición de nuevas relaciones internas al 'texto de llegada' entre las propias huellas y su enunciado: "se trata de relaciones tan determinantes, que inducen a la afirmación de que en los textos audiovisuales el enunciado es difícilmente separable de la impronta de la enunciación, porque está siempre impregnado de modalidad." (Bettetini, 996: 87).

Dadas estas dificultades, que conllevan la preponderancia de la autonomía semiótica respecto del discurso originario, Bettetini llega incluso a dudar de la legitimidad del uso de traducción, y anota, para confirmar esta tendencia, el hecho de que en la práctica audiovisual se hable de reducción, y que en ésta se haga referencia a los textos literarios de base con formulaciones como "libremente tratado por" "libremente inspirado en" "sobre una idea de"; agrega que en estos casos la traición frente al texto de partida forma parte conscientemente del proyecto de traducción y no se refiere sólo al ámbito pragmático. 
No obstante se empeña en hacer un recorrido que permita apreciar las posibilidades de este tipo de ejercicios transformadores. Insiste en que las operaciones semióticas más fáciles de traducir son las narrativas, a las que considera translinguísticas. La fábula, las organizaciones abstractas, los valores, así como las acciones, los actores, las funciones y los actantes podrían ser transferidos al discurso audiovisual sin mayor dificultad, siendo respetados fielmente. No obstante, habría una diferencia sustancial: en la literatura cualquier representación, por detallada que pudiera ser como pasa con algunas descripciones -porque se realiza por medio de signos abstractamente simbólicos-, dejaría librado a la imaginación un margen muy amplio de interpretación, mientras que en el texto audiovisual, todo se definiría en una semiosis mucho más restringida y direccional -dado que ésta se manifiesta por medio de signos icónicos fuertemente motivados-.

Otra dificultad en el pasaje transemiótico de narraciones tendría que ver con las diferencias en la temporalidad. Así, mientras que el tiempo de lectura no estaría determinado por el tiempo de escritura, el tiempo de la "escritura audiovisual" si sería restrictivo y direccional frente al disfrute, lo que hace que sea considerado como un componente importante de producción de sentido que se trata de desplegar. Mientras que el lector tendría una relación libre con el texto literario, que lo facultaría para hacer saltos retrocesos y detenciones, la recepción audiovisual se encontraría en una relación de consumo con los textos audiovisuales completamente dirigida por la articulación temporal de su enunciación $(1996,89)$.

Es innegable que las operaciones narrativas son las más prestas a la transposición, es por esto que los trabajos que indagan este fenómeno semiótico han proliferado ante todo en la consideración del pasaje de narraciones. No obstante no deben ignorarse que también se transponen descripciones y hasta argumentaciones -o al menos núcleos argumentativos -como parece ocurrir en algunas transposiciones del género de ciencia ficción-; así como tampoco debe descuidarse el hecho de que las narraciones se articulan de manera compleja con las descripciones y las argumentaciones, circunstancia que ha de ser tomada en cuenta en la consideración de transposiciones concretas. 
También es innegable que existe una asimetría considerable en las relaciones entre el tiempo de lectura y el de escritura entre la literatura y los audiovisuales, sin embargo, es preciso recordar que las posibilidades de retroceso, saltos adelante o las pausas, también existen en la lectura de textos audiovisuales hace ya bastante tiempo, desde que existen las videograbadoras, tanto porque es posible disponer de copias de filmes como porque es posible grabar en casa programas televisivos o hasta comprarlos -como ocurre con las ediciones por capítulos de telenovelas en Latinoamérica- y con las series de televisión en Estados Unidos, para no hablar del recurso del DVD y los discos de diversos formatos que pueden ser visualizados en videograbadoras o en computadoras. No está demás decirlo, este recurso técnico ha hecho posible la aparición de otras maneras de leer los audiovisuales que redundan en vínculos estéticos muy particulares de los receptores con los productos y con los géneros, donde no se puede desestimar la crítica, la erudición y hasta cierta "mística"; circunstancia que hace posible también un mejor trabajo para el analista. ${ }^{5}$

5 Por cierto, este dispositivo guarda similitud con la televisión -utiliza sus técnicas y las combina con otras- pero se aparta de ésta en múltiples aspectos que merecen ser estudiados, algunos tienen que ver con la conformación de un circuito comercial -de producción y circulación- dependiente de la industria cinematográfica. La recepción no está pautada por las programadoras de televisión que imponen los ritmos y los tiempos de las audiencias. Pero al lado de este circuito oficial de venta y alquiler; se encuentran los de descargas en línea tan perseguidos últimamente por la justicia estadounidense, así como otros circuitos singularizados más vinculados a los gustos y al capricho, que se beneficia, entre otras cosas, de las posibilidades que la Internet ofrece. Ni que decir que las condiciones de recepción se modifican radicalmente, empezando porque se rompe el encuadre de la sala oscura y porque se abre paso a la manipulación directa del producto audiovisual por parte del espectador, que pasa por esta vía a tener un vínculo muy personal con estos productos. Por otra parte, esta circunstancia de la posibilidad de manipulación técnica de reproducción, y hasta de edición de las obras cinematográficas, lleva al extremo la tendencia señalada por Benjamin de destrucción del aura por la reproductibilidad técnica. 
Otra anotación de Bettetini en esta dirección nos recuerda que la disposición de la velocidad en la sucesión narrativa audiovisual debe ocuparse de ciertas condiciones perceptivas que obligan a guardar ciertas normas, o de lo contrario los textos serían ininteligibles, y que la articulación temporal sobre la relación lector-espectador con el texto conlleva adaptaciones, supresiones y en general reducciones, en el paso de la literatura al audiovisual.6 Sólo precisamos anotar a este respecto que, en todo caso, esas condiciones perceptivas que regularían las posibilidades de la comprensión y que por ello condicionan la disposición de la sucesión narrativa, no son algo estricto, establecido de una vez, sino que son culturales e históricas y cambian con el tiempo y con los contextos según las distintas maneras de relacionarse con los dispositivos técnicos y según otras condiciones culturales. ${ }^{7}$ Piénsese por ejemplo, en las competencias de velocidad de lectura de las que disponen los consumidores de videoclips, e incluso piénsese en ciertos filmes cuya configuración estética se regodea en el juego de las aceleraciones y las distorsiones; e incluso en las tradiciones cinematográficas nacionales y en los géneros, para no hablar de las construcciones nada convencionales del cine de vanguardia. En general, la velocidad promedio del cine más comercial ha ido variando de modo que al ver filmes viejos de hace tres o cuatro décadas es fácil tener la sensación de que se trata de filmes muy lentos; sensación que se agudiza si el espectador es un joven de las actuales generaciones; pero lo mismo ocurre -aunque seguramente no de manera absoluta- si se compara filmes europeos con filmes estadounidenses.

En relación con estos aspectos menciona también el caso de la extensión convencional de los textos audiovisuales, que en el caso de los filmes

6 Otro tanto ocurriría con la duración, cuya concentración sería impuesta pragmáticamente por el sistema productivo y distribuidor, y que derivaría la necesidad de elecciones que destacan algunos aspectos del enunciado narrativo en desmedro de otros de transformaciones semióticas que tenderían a reproponer el primitivo sentido, al menos, a nivel de una cita o un reenvío.

$7 \quad$ Los cambios en el sensorium de los que hablan Benjamin (1973), y a partir de él, Martín Barbero (2003). 
coincidiría más en la transposición del cuento o de la novela corta, pero en todo caso no de la novela tradicional, que "en su paso a la pantalla, corre el riesgo de reducirse a un armazón genérico, a la propuesta de una fórmula iterativa de narración." (1996: 90-91).

Por ello anota que la televisión ofrece otras posibilidades, por tener formatos caracterizados por duraciones más largas, que facilitan, por ejemplo, organizar la narración en capítulos, teniendo así “la posibilidad de una exposición narrativa más fiel a la novela original de la que puede tener el cine" (1996). Estas observaciones, a primera vista evidentes, no dejan de ser superfluas si se pregunta detenidamente por cuál fidelidad es a la que se alude ${ }^{8}$ y si se repara en que, si bien la extensión proporciona condiciones favorables si se busca la fidelidad, no llega sin embargo a definir su eficacia, pues un recurso condensador o incluso una alusión o indicación - de atmósferas por ejemplo- bien dispuesto puede ser mucho más propicio y certero que un intento de recreación "fiel", y que, como lo indica el mismo Bettetini y como lo plantea Wolf (2004), ${ }^{9}$ muchas veces cuanto más se persigue la fidelidad tanto más se aleja uno de ella.

Otro asunto, que justamente preocupa tanto a Bettetini, es el de las posibles disociaciones del sujeto enunciador en uno o varios sujetos "narradores". A propósito, nuestro autor encuentra que, de las posibilidades que la literatura ha desarrollado: contar impersonalmente, construir un origen localizado en un "yo" narrador que se dirige a un "tú" lector, disociar el narrador en varios actantes que pueden coincidir con actantes de la narración o que pueden no estar implicados en el universo del relato; la primera sería la más propicia para la traducción audiovisual y la segunda la más difícil, pues en el audiovi-

8 Recuérdense las anotaciones hechas por Borges en Las Versiones homéricas (1979).

9 Sergio Wolf en Cine/Literatura: Ritos de pasaje (2004), insiste en el error de asumir rutinariamente o de manera naturalizada la eficacia en el uso de determinados procedimientos cinematográficos con la creencia y el propósito de acercarse a procedimientos similares en el texto literario. 
sual no se toleraría la identificación con sujetos empíricos, no obstante señala que en estos casos se suele apelar al uso de la llamada voz en off.

Concluye que, por más dificultades que se encuentren, es posible traducir en principio cualquier narrativa a un texto audiovisual. En cambio encuentra mucho más difícil traducir el comentario, y que su traducción implica siempre un trabajo de reescritura y replanteamiento de la estructura enunciativa que puede llevar a cuestionar los aspectos narrativos. El comentario tendería a desaparecer del texto audiovisual, pues en este se tiende a borrar al sujeto enunciador y, en consecuencia, su instancia comentativa aparecería propuesta como "dimensiones orgánicas del universo posible construido por su trabajo semántico, que es después el universo producido por la narración." (Bettetini, 1996: 94).

Termina reconociendo que, por más que el sujeto enunciador no sea más que un aparato cultural ausente o un simulacro inmanente al texto, esta construcción está regida por proyectos e hipótesis muy distintos en el campo literario y en el audiovisual. “Las diferencias son fundamentales, sustanciales, y los dos ámbitos productores del sentido, desde este punto de vista, no son de hecho conmensurables." (1996).

Como puede apreciarse, el enfoque teórico de partida de Bettetini con respecto a la enunciación en el cine, lo lleva a no reconocer sus propias elaboraciones o a no ser consecuente con ellas, pues, si es posible encontrar semejanzas y diferencias enunciativas entre textos y géneros literarios y audiovisuales, no es necesario caer en el terreno de la inconmensurabilidad, si no se concibe a la enunciación como algo identificable con un sujeto empírico o con un sujeto antropoide. ${ }^{10}$ Su impasse se hace aun más evidente

10 Ni siquiera en el ámbito estrictamente lingüístico o literario es necesaria tal identificación. Aunque desde marcos teóricos distintos, coinciden en esta manera de apreciar las cosas tanto Verón (Posmodernidad y teorías del lenguaje: el fin de los funcionalismos, 1985) como Ducrot (El decir y lo dicho, 1986), y los dos coinciden o tienen, eso sí, como punto de partida, una crítica a la concepción del sujeto en la pragmática anglosajona. 
en una afirmación como la siguiente:

\begin{abstract}
La traducción entre sistemas semióticos distintos, caracterizados por pragmáticas distintas, debe tener en cuenta la transformación de la relación comunicativa creada por el cambio de textualidad. Traducción significa también, en este caso, respeto de las instancias pragmáticas del primer texto, a pesar de la innovación comunicativa implícita en el paso al segundo; si esto no es posible ly en su totalidad traslativa no lo puede ser nunca), traducir significa operar una serie de elecciones reductivas y transformativas en confrontación con el texto originario, significa proyectar un texto nuevo más o menos motivado, semántica y pragmáticamente por el original. (Bettetini, 1996: 97).
\end{abstract}

Se advierte una tensión entre una concepción problemática y limitada de la enunciación y las conclusiones que una indagación concreta del fenómeno audiovisual se le imponen al autor, de allí que, a pesar de su exigencia de respeto y fidelidad, al final se deslice hacia una consideración de las operaciones transemióticas que no coincide con su noción de partida de traducción, por eso habla de "proyectar un texto nuevo más o menos motivado, semántica y pragmáticamente por el original”.

\title{
Metz: hacia una teoría no antropoide de la enunciación fílmica
}

Metz (1991) se encarga de proponer una noción renovada de enunciación, a partir de su investigación específica sobre el lenguaje cinematográfico, esta noción trata de apartarse de la consideración deíctica -predominante- del funcionamiento enunciativo, y por tanto trata de desantropomorfizarlo, al mismo tiempo esta reconversión de la noción, como el mismo la llama, le permite dar cuenta de manera mucho más acertada de las peculiaridades del filme. Así, Afirma que hablar de enunciador y enunciatario para describir el funcionamiento enunciativo propio del filme conlleva a través del sufijo de dichos términos connotaciones irremediablemente antropomórficas, en 
cambio él propone los de foyer (fuente) de la enunciación y blanco, destinación u objetivo de la enunciación, pues éstos remiten a cosas, como es el caso en el cine donde todo descansa sobre máquinas. ${ }^{11}$

Comenta que, de hecho, la interacción directa que posibilita un funcionamiento deíctico en sentido estricto, que posibilita una genuina reversibilidad -que yo se torne tú y tú se torne yo- sólo funciona en la conversación oral cara a cara, y que este no es el caso ya en comunicaciones verbales escritas que transcriben ese tipo de intercambios, así como no lo es ya tampoco en la historia, no funciona sobre todo tampoco en el intercambio literario y, por supuesto, mucho menos en intercambios pictórico ni cinematográfico.12

Insiste en que no tiene sentido llamar $\mathrm{YO}$ a un yo que no puede tornarse en tú, a la fuente de un discurso no interactivo -en la novela o en el cine- si no conceden a la enunciación y al lector-espectador ninguna posibilidad de modificación, salvo acciones puramente exteriores como cerrar el libro o apagar el televisor. Comenta también que la propia actitud de los usuarios de textos audiovisuales nada tiene que ver con dicha antropomorfización

11 Metz discute centralmente con Casetti, a quien se refiere como al más importante teórico actual de la semiótica del filme. Así, menciona como este autor, impregnado de esta concepción deíctica de la enunciación, por más que trate de ponerse y de ponernos sobre aviso en su contra, construye un dispositivo interpretativo expresamente montado sobre las figuras deícticas: "Así, para la mirada a cámara: YO (: enunciador) y EL (: personaje) TE (: enunciatario) miramos, y así siguiendo para las grandes 'formas' que dibuja la enunciación.". Pero también con Bettetini, al que le reprocha de entrada el nombre de su libro La conversación audiovisual.

12 Incluso aclara que aun en el intercambio cara a cara "se tiene la impresión de que ver, o tocar, al foyer y al blanco de la enunciación (quienes en realidad se sustraen a ese contacto, pues consisten en pronombres gramaticales). Se los confunde, aquí, todavía con sus instancias de encarnación, con las dos personas que conversan: lo que se toma por el foyer de la enunciación es otro enunciado, simultáneo, el enunciado mímico-gestual del sujeto que habla, es decir de la propia persona (de ahí la confusión)." (1991, 121) 
-introducida por los especialistas- "pero lo más corriente es que ese espectador no piense ni en el imaginero. No cree, tampoco, por el contrario, que las cosas se revelen por sí mismas: simplemente ve imágenes".13

Según Metz, lo enunciativo en el cine tendría que ver con las capacidades metadiscursivas del filme, por las cuales éste nos habla de sí mismo o del cine, con su capacidad de plegarse sobre sí mismo. Pero, en todo caso, no se trata de algo que tenga que ver con alguna instancia puesta a mitad de camino entre el filme y fuera del filme, sino de diversas configuraciones textuales que se encuentran siempre dentro del propio filme, que es, en definitiva, lo único que tenemos.

La enunciación fílmica es siempre una enunciación sobre el filme. Metadiscursiva más que deíctica, nos informa no sobre algo exterior al texto, sino sobre un texto que lleva en sí mismo su foyer y su destinación. (..) El foyer y la destinación, considerados en su inscripción literal, en su identidad discursiva, no son papeles sino fragmentos de texto, o aspectos del texto o configuraciones del texto lasí el campocontracampo se observa organización general de la sucesión de imágenes). Antes bien orientaciones, vectores en una topografía textual de instancias más abstractas de lo que en general se dice. (...) la enunciación, es preciso volver a decirlo, no se reduce a 'marcas' localizadas y distinguibles entre sí l: concepción antropoide: las huellas de los pies del Sujeto semi-humano ubicado afuera- adentrol sino que es coextensiva al filme y se halla presente en la composición de cada plano: no siempre marcada pero en todo lugar actuante. (Metz, 1991: 133- 135)

13 “Toda concepción de la enunciación muy marcada por la deixis comporta, desde el momento en que se la separa del estudio de los intercambios hablados, tres riesgos principales, antropomorfismo, traslación lingüística y deslizamiento de la enunciación hacia la comunicación (: relaciones 'reales', extratextuales). El mismo Casetti no cede a menudo a estas tentaciones, nos pone en guardia contra ellas, pero en teoría, el riesgo permanece l'el riesgo', en singular, pues los tres no hacen sino uno, son indisociables)." (130). 
De manera que, al considerar las relaciones entre un texto fuente y su transposición audiovisual, y dentro de ellas las que se refieren a los rasgos enunciativos, podemos considerar el pasaje sin quedar anclados a las exigencias de fidelidad o respeto del programa pragmático del sujeto de partida presupuesto como fuente del "original".

\title{
Chatman: 0 la identificación primaria con el texto literario y la ausencia de una teoría de la enunciación
}

Por su parte Seymour Chatman (1980: 122) en What Novels Can Do That Films can't land Viceversal. Lo que las novelas pueden hacer que las películas no pueden (y viceversal se ocupa también del fenómeno transpositivo, si bien guiado por el interés específico de comparar las peculiaridades de estos dos lenguajes. Para empezar enuncia una tesis compartida por muchos narratólogos.

\begin{abstract}
La narrativa es una honda estructura bastante independiente de su medio. Es una clase de organización de textos y esa organización, ese esquema necesita ser hecho realidad con palabras escritas, como en cuentos y novelas; en lenguaje hablado combinado con los movimientos de los actores que imitan personajes y decoraciones que imitan lugares, como en obras de teatro y películas; en pinturas; en tiras cómicas; en movimientos de danza; en ballet narrativo y en mímica; e inclusive en música." (1980).
\end{abstract}

Chatman se refiere a la doble temporalidad como lo que define a la narración, tiempo de la historia y tiempo discursivo como tiempos independientes, algo que persiste en ella cualquiera sea el medio en el que se asiente. Anota que esta peculiaridad de las narraciones fue encontrada como algo que posibilitaba la traslación de un texto narrativo de un medio a otro, y que esta observación es interesante por sus relaciones con el estructuralismo y por lo productivo que se hizo más tarde el análisis narrativo. Señala sin embargo 
que esta circunstancia condujo a que se centrará la atención exclusiva en las estructuras narrativas que eran constantes, descuidando así diferencias muy importantes. Sus estudios sobre retórica de la literatura y los audiovisuales lo habrían conducido a una mirada más atenta de dichas diferencias, relacionadas con las peculiaridades de los medios. En el texto comenta dos casos, la descripción y el punto de vista.

Empecemos con el primer caso que es al que le dedica más espacio, la descripción. Chatman explica que la descripción descansa sobre la estructura temporal, lo que sucede con ésta es que el tiempo de la historia es interrumpido y congelado, aunque el tiempo discursivo siga su marcha los eventos se paran. Sostiene que esto no ocurre en el cine, que de hecho no hay descripción propiamente dicha en el cine porque en este el tiempo de la historia no se detiene; afirma también que la clave está en que el cine no asevera, sólo muestra, no detalla por más que contenga operaciones que sugieran esa dirección, y que aun si hubiera una larga pausa que posibilitara observar gran cantidad de detalles -cosa que no ocurre regularmente en el cine- aun sentiríamos que el reloj del tiempo de la historia sigue su marcha, que la pausa ha sido incluida en la historia y que no es un intervalo, como si nos parece al leer en el libro. Así mismo agrega que lo que predomina en el cine es la fuerza de la narración que va demasiado rápido, y por ello no hay lugar para detenerse en los detalles. De modo que:

En cualquier caso, el sentimiento de que estamos compartiendo un paso del tiempo con un personaje, debería ser un claro indicio de que no solamente nuestro tiempo discursivo sino también el tiempo de la historia de los personajes continúa rodando. Y si es cierto que el tiempo de la historia continúa rodando en las películas, y si describir supone precisamente la detención del tiempo de la historia, entonces es razonable argumentar que las películas no pueden describir.(Chatman, 1980:129). 
Chatman hace consideraciones muy precisas para ilustrar ese tipo de diferencias, como puede apreciarse, no obstante también hace algunas afirmaciones que dejan ver una actitud prejuiciosa hacia el lenguaje cinematográfico, actitud que se funda, a nuestra manera de ver, en una suerte de “identificación primaria” del analista con los textos literarios. Junto con esto encontramos en sus planteamientos una apreciación del lenguaje cinematográfico que no ha sabido asumir la complejidad del carácter impuro, combinado, del mismo. Además de que su concepción teórica se ve debilitada por su no incorporación de una teoría de la enunciación.

Encontramos, de conjunto, una apreciación más justa de la naturaleza del lenguaje cinematográfico, y dentro de él, de las relaciones entre lengua e imagen en los trabajos de Gaudreault y Jost (2001), y antes que ellos en los de Jean Mitry que Metz comenta y en los del mismo Metz (2002) [1966].

Chatman llega a afirmar que:

Inclusive los sofisticados cinéfilos que llaman a una película 'hermosa', se están refiriendo más a su literatura que a los componentes visuales (...) La contemplación de hermosos escenarios, o color, o luces es un placer limitado a aquellos que pueden ver la película varias veces, o aquellos que afortunadamente tienen acceso al equipo que les permite parar la imagen. (Chatman, 1980: 126).

Y que, en los casos en los que se apela a un personaje o a la voz de un comentarista que asevera una propiedad o una relación, esto no puede ser tomado como una descripción fílmica, se trataría más bien de descripción por aserción literaria transferida a la película. 0 que la cámara no posee el don de la invocación del tono, es decir, que la cámara no nos dice nada acerca del que filma.

Es cierto que el cine no acostumbra detenerse demasiado en los detalles, salvo en películas muy particulares y que, en todo caso, aun cuando lo hace esto no funciona como una aseveración estricta, pero decir que en el cine 
no se pueden apreciar los detalles porque lo que predomina es la narrativa y porque se va muy rápido, es medir los fenómenos de la percepción fílmica con el rasero de la percepción y la experiencia literaria. De allí que resulte en extremo arbitrario afirmar que quien diga que una película es bella sólo puede hablar de la narrativa pues no habría tenido tiempo de apreciar los detalles, el paisaje, el color; pues, de hecho, cuando un cinéfilo afirma que una película es bella puede decirlo pensando en muchas cosas, y en muchas ocasiones se refiere explícitamente al color, a la fotografía, a los paisajes. Es decir que existen otras velocidades, otras maneras de percibir en el cine que no excluyen el gozar de los detalles. Se advierte que pesa mucho el prejuicio del valor de lo literario sobre los otros lenguajes, y que se descuidan las especificidades perceptuales que las materias imponen a los lenguajes.

En cuanto al segundo caso, aquello de que cuando se apela a la voz de un personaje o a la de un comentarista no se lo está describiendo fílmicamente sino transcribiendo una descripción literaria al filme; esto revela que Chatman considera la banda de sonido como algo agregado, accesorio al filme, en lugar de considerarlo como una parte integral suya, y que, en consecuencia, es otra posibilidad de describir en el cine; pero más aun, es necesario insistir en que el cine no es sólo imagen en movimiento, y que hace mucho tiempo que nadie imagina el cine por fuera de su compleja articulación de lenguajes y que incluso, como lo plantean Jost y Gaudreault (2001), el cine siempre ha sostenido una relación con la palabra, que la presupone como una parte suya. Además, es sabido que existen otros procedimientos fílmicos para describir, piénsese por ejemplo en el papel que juegan los detalles en los filmes policíacos o de suspenso, en estos los detalles son centrales y los procedimientos suelen ser ante todo visuales, y son tan centrales que cuentan como indicadores, al punto que parecieran poder decir, he ahí tal comportamiento...he ahí tal personaje, con una economía visual y la exigencia de una complicidad del público sin la cual estas películas no podrían ser vistas.

Chatman plantea también que la cámara no tiene tampoco el poder de invocar el tono -cuando el lenguaje es capaz de contarnos algo del que nos habla-, como en el caso que comenta, en el que quien describe está apenas adivinan- 
do no aseverando- y parece ser alguien proclive a los encantos femeninos. Pero de lo que se trata en realidad es de la posibilidad de producir ciertos efectos, de modalizar lo que se dice, de insinuar, de apenas mostrar, de dejar en la ambigüedad, o incluso de mostrar detalladamente y después sugerir apenas otra posible interpretación. Pero hemos de insistir en que todos estos son posibles efectos enunciativos, tanto en la literatura como en el cine, que sólo pueden ser juzgados en la recepción. Como puede apreciarse, Chatman se apresura a señalar una incapacidad del cine -y una fortaleza de la literatura- que sólo tiene lugar si se asume en extremo naturalizada la relación con los textos literarios. En definitiva, se habla desde la perspectiva de un lector literario cómplice (que no ha podido escapar a su identificación primaria con un soporte) y que se olvida de que el cine también puede ser leído -y de hecho lo es - en una relación de complicidad entre la fuente y el destino. Esto tiene que ver con su olvido -o desentendimiento- de la teoría de la enunciación, lo que le resta posibilidades para comprender determinados efectos narrativos que, bien pueden ser explicados como efectos enunciativos.

También se ocupa de mostrar muy bien cómo el cine puede resolver problemas, a la hora de transponer una narración literaria, apelando a sus propias posibilidades técnicas. Como ocurre con los puntos de vista. Aclara que, ante la dificultad de mostrar una condición ambigua de un personaje -el hecho de ser a la vez inocente y seductora-, estas dificultades pueden dar lugar a respuestas creativas como la de Renoir cuando, “como seducción y belleza están en el ojo del observador, Renoir utiliza el punto de vista de Rudolphe para mostrarlo." Y logra mostrar cómo la bella chica Henriette es atractiva y seductora aunque ella no se lo proponga, mostrando como despierta admiración en muchos hombres de distintas generaciones. Esto acontece con la transposición del cuento de Guy de Maupassant Une partie de Champagne que tiene el mismo nombre.

Sin embargo, a propósito del mismo ejemplo de la transposición, el caso ambiguo de la seductora inconsciente, insiste en que no se podrían describir los detalles corporales del mismo personaje, e incluso que al afirmar que la chica en cuestión es bella en el texto literario es difícil hacer lo mismo en el texto cinematográfico, pues en el cine se tendría la dificultad de tener 
que contar con el consenso del público acerca de lo que se considera una mujer bella.

Para empezar, lo último sólo tiene sentido si se está juzgando la película en su relación con el texto literario, es decir que no puede considerarse en sí mismo como una limitación cinematográfica, pues de otra manera no se entendería que haya alguna dificultad. En la película se apelaría a una imagen considerada bella por los que hacen la película si esa es su intención y, seguramente tendrán muchos puntos de referencia en el medio cultural en el que se hayan inscritos y/o al cual dirigen su producto audiovisual. Luego, la exigencia de esa adecuación o consenso sólo se puede entender aquí, como una exigencia de fidelidad. Sólo si se exige fidelidad al texto literario podría surgir una preocupación o dificultad como la que el autor invoca, que la imagen cinematográfica coincida con la descripción del cuento. Pero también podría ocurrir que, aunque se parta del texto literario, se quiera mostrar otra cosa, o mostrar la misma cosa de otra manera, puede ser que se quisiera reinterpretar algún aspecto del texto fuente y por ello, por ejemplo, se presente deliberadamente otro perfil de belleza femenina apartándose del propuesto por el escritor. 0 incluso, como suele ocurrir, que no se quiera o se busque ninguna de las opciones anteriores y que, no obstante, éstas tengan lugar, simplemente, por el efecto de desplazamiento que el tránsito por un dispositivo técnico incrustado en el circuito de la comunicación de masas, con el lastre de su memoria narrativa, o una lectura de época, pueden traer sobre un texto, dejando huellas de todo tipo, estilísticas, técnicas o ideológicas.

No obstante aun se pueden hacer algunas precisiones sobre el asunto mismo de la descripción que Chatman discute. En realidad se trata de tres y no de dos temporalidades, la de la historia, la del discurso, y la de la lectura, Chatman confunde el tiempo discursivo con el tiempo de lectura; si bien es cierto que en cine, en cuanto arte temporal, el tiempo de la lectura suele ser un tiempo de la relectura que tiene lugar gracias a los instrumentos de grabación. Es preciso anotar también que otros autores, como Genette (1998) y como Eco (1996), no ven tan rígida la distinción. La descripción se entiende también más como detención que como desaceleración y, de cualquier manera, puede tener múltiples sentidos en el texto, sentidos asociados a distintas 
temporalidades, según Eco algunos son: (tiempo del espasmo, tiempo del extravío, tiempo de la insinuación, y tiempo para dar impresión de espaciol (Eco, 1996, 74-82). En estos casos la descripción estaría al servicio de la delectación morosa, de la imposición de un determinado ritmo, y para cuyos fines se hacen coincidir o no los tres tiempos; pero en todo caso todo esto depende de las posibilidades de encontrar un lector modelo -destinatario ideal- que asuma el ritmo que se le propone. Como puede observarse, siempre reaparecen las cuestiones enunciativas de por medio. A todo lo anterior debemos agregar, como lo cuenta Steimberg (1998: 102), que, justamente, es posible que una transposición reinterprete y ponga en cuestión un verosímil novelístico por el hecho de abundar en descripciones que no aparecían marcadas así en el texto literario, modificando las relaciones entre relato y descripción. Tal es el caso de Luchino Visconti, que transforma en un exponente de una narrativa de época lo que en el texto fuente sólo eran estereotipos paisajísticos propios de su momento estilístico.

Ahora bien, si puede aceptarse que es distinto atribuir cualidades a personajes o cosas al escribir que al hacer una película, algo que parece razonable, no se debe descuidar que, en todo caso, una cosa es atribuir y otra es describir, y que otra es tener consenso con los receptores respecto de la justeza de la descripción; es decir que un escritor puede afirmar o decir que un personaje es bello pero esto no es lo mismo que reconocer que haya logrado el efecto de sugerir al lector, con y por su descripción, que es bello en efecto. Lo que deseo sostener es que si se trata de dicha eficacia también el escritor se las tiene que ver con lo que el lector ponga en la recepción, pues no sólo se trata de si es un buen descriptor (Hamon, 1991) sino de si las cosas que describe y califica de bellas lo son también para los lectores, lo que indica que el texto literario no se encuentra muy lejos, en este terreno, de la situación de la película. Evidentemente Chatman incurre en debilidades que proceden de su desentendimiento de la teoría de la enunciación.

En definitiva, todas estas dificultades tienen que ver con las tribulaciones de una búsqueda semiótica y narratológica que intenta adecuarse a las particularidades del lenguaje cinematográfico inspirada en los desarrollos de la lingüística y de la narratología de la literatura, búsqueda que sigue su 
marcha y a la que no podemos reprochar nada, excepto que sepa reconocer que la propia semiótica y narratología del cine está encontrando sus propias herramientas, que incluso pueden servir de apoyo a otros ámbitos semióticos y narratológicos, lo que implicaría abandonar lo que he denominado los prejuicios. De cualquier manera, a los fines de nuestra búsqueda específica, estas disquisiciones cuentan como un recurso en procura de aclarar y desnaturalizar las representaciones acerca de las relaciones entre uno y otro lenguaje, asunto indispensable a la hora de estudiar los pasajes transsemióticos entre los mismos.

Pero esto nos lleva a pensar también que el problema transpositivo no puede ser reducido a un asunto de posibilidades técnicas, sin que se crea que éstas no hacen parte del asunto transpositivo, sino que es preciso considerar múltiples aspectos discursivos relacionados con las condiciones sociales de producción y con la circulación; con el desfasaje entre producción y reconocimiento y con los imponderables de las lecturas de época en su compleja articulación con las técnicas y los medios, sin los cuales el análisis quedaría reducido a una consideración inmanente de las relaciones entre textos y entre medios. 


\section{REFERÊNCIA BIBLIOGRÁFICA:}

BETTETINI, Gianfranco. La conversación audiovisual. Madrid. Cátedra, 1996.

BORGES, Jorge Luis. Las versiones homéricas. En: Obras completas. Buenos Aires: Emecé, 1979.

CASETTI, Francesco y Di CHIO, Federico. Cómo analizar un film. Buenos Aires: Paidós, 1998.

CHATMAN, Seymour. “What Novels Can Do That Films Can't land Vice Versa)”. En: Critical Inquiry, Vol. 7, No. 1, On Narrative (Autumn, 1980), pp 121-140.University of Chicago Press. http://www.jstor.org/stable/1343179

CHATMAN, Seymour. Historia y discurso: La estructura narrativaa en la novela y en el cine. Madrid: Taurus, 1991.

DUCROT, Oswald. El decir y lo dicho. Barcelona: Paidós, 1986.

ECO, Umberto. Seis paseos por los bosques narrativos. Barcelona: Lumen, 1994.

GENETTE, Gerard. Palimpsestos. Madrid: Taurus, 1989. --------. Nuevo discurso del relato. Madrid: Cátedra, 1998.

GAUDREAULT, André y JOST, Francois. El relato cinematográfico: Ciencia y narratología. Barcelona: Paidós, 1995.

HAMON, Philippe. Introducción al análisis de lo descriptivo. Buenos Aires: Edicial, 1991.

MARTíN-BARBERO, Jesús. De los medios a las mediaciones. Bogotá: Convenio Andrés Bello, 2003.

METZ, Christian. La enunciación antropoide, En, La Enunciación impersonal. 0 la visión del filme, Meridiens Klincksieck, París, 1991. Traducción aparecida en el cuaderno de la materia semiótica II, Cátedra Del Coto, Materia unidad 4 Teórico. Ciencias de la comunicación, Facultad de Ciencias Sociales, UBA, Buenos Aires.

."Problemas actuales de la teoría del cine". En: Ensayos sobre la significación en el cine, Vol 2. Barcelona: Paidós, 2002. 
STEIMBERG, Oscar. Semiótica de los medios masivos: el pasaje a los medios de los géneros populares. Buenos Aires: Autel, 1998.

VERÓN, Eliseo. Fragmentos de un tejido. Barcelona: Gedisa, 2004.

WOLF, Sergio. Cine/Literatura: Ritos de pasaje. Buenos Aires, Paidós Estudios de Comunicación, 2004. 